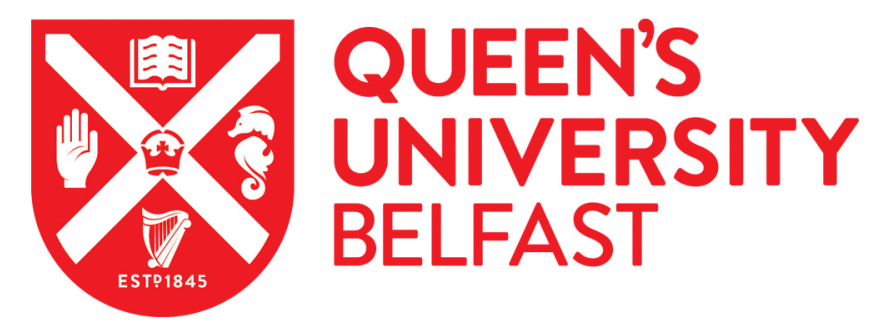

\title{
Yield and arsenate uptake of arbuscular mycorrhizal tomato colonized by Glomus mosseae BEG167 in As spiked soil under glasshouse
} conditions

Liu, Y., Zhu, Y. G., Chen, B. D., Christie, P., \& Li, X. L. (2005). Yield and arsenate uptake of arbuscular mycorrhizal tomato colonized by Glomus mosseae BEG167 in As spiked soil under glasshouse conditions. Environment International, 31(6), 867-873. https://doi.org/10.1016/j.envint.2005.05.041

Published in:

Environment International

Queen's University Belfast - Research Portal:

Link to publication record in Queen's University Belfast Research Portal

\section{General rights}

Copyright for the publications made accessible via the Queen's University Belfast Research Portal is retained by the author(s) and / or other copyright owners and it is a condition of accessing these publications that users recognise and abide by the legal requirements associated with these rights.

\section{Take down policy}

The Research Portal is Queen's institutional repository that provides access to Queen's research output. Every effort has been made to ensure that content in the Research Portal does not infringe any person's rights, or applicable UK laws. If you discover content in the Research Portal that you believe breaches copyright or violates any law, please contact openaccess@qub.ac.uk. 


\title{
Yield and arsenate uptake of arbuscular mycorrhizal tomato colonized by Glomus mosseae BEG167 in As spiked soil under glasshouse conditions
}

\author{
Y. Liu ${ }^{\mathrm{a}, \mathrm{b}}$, Y.G. Zhu ${ }^{\mathrm{b}}$, B.D. Chen ${ }^{\mathrm{b}}$, P. Christie ${ }^{\mathrm{a}, \mathrm{c}}$, X.L. Li ${ }^{\mathrm{a}, *}$ \\ ${ }^{a}$ China Agricultural University, Department of Plant Nutrition, 2 Yuanmingyuan Road, Beijing 100094, PR China \\ ${ }^{\mathrm{b}}$ Chinese Academy of Sciences, Research Center for Eco-Environmental Sciences, Department of Soil Environmental Science, Beijing 100085, PR China \\ 'Queen's University Belfast, Agricultural and Environmental Science Department, Newforge Lane, Belfast BT9 5PX, UK
}

Available online 27 June 2005

\begin{abstract}
A glasshouse pot experiment was conducted to study the effect of arbuscular mycorrhizal (AM) colonization by Glomus mosseae BEG167 on the yield and arsenate uptake of tomato plants in soil experimentally contaminated with five As levels $(0,25,50,75$ and 150 mg $\left.\mathrm{kg}^{-1}\right)$. Mycorrhizal colonization (50-70\% of root length) was little affected by As application and declined only in soil amended with 150 $\mathrm{mg} \mathrm{As} \mathrm{kg}{ }^{-1}$. Mycorrhizal colonization increased plant biomass at As application rates of 25, 50 and $75 \mathrm{mg} \mathrm{kg}^{-1}$. Shoot As concentration increased with increasing As addition up to $50 \mathrm{mg} \mathrm{kg}^{-1}$ but decreased with mycorrhizal colonization at As addition rates of 75 and $150 \mathrm{mg}$ $\mathrm{kg}^{-1}$. Shoot As uptake increased with mycorrhizal colonization at most As addition levels studied, but tended to decrease with addition of $150 \mathrm{mg} \mathrm{As} \mathrm{kg}{ }^{-1}$. Total P uptake by mycorrhizal plants was elevated at As rates of 25,50 and $75 \mathrm{mg} \mathrm{kg}^{-1}$, and more P was allocated to the roots of mycorrhizal plants. Mycorrhizal plants had higher shoot and root P/As ratios at higher As application rates than did non-mycorrhizal controls. The soil of inoculated treatments had higher available As than uninoculated controls, and higher $\mathrm{pH}$ values at As addition levels of 25,50 and $75 \mathrm{mg} \mathrm{kg}^{-1}$. Mycorrhizal colonization may have increased plant resistance to potential As toxicity at the highest level of As contamination studied. Mycorrhizal tomato plants may have potential for phytoextraction of As from moderately contaminated soils or phytostabilization of more highly polluted sites.
\end{abstract}

(C) 2005 Elsevier Ltd. All rights reserved.

Keywords: Arsenic; Arbuscular mycorrhiza; Phytoextraction; Phytoremediation; Phytostabilization; Soil contamination

\section{Introduction}

Land plants that are adapted to contaminated soils are generally symbiotic with mycorrhizal fungi (Cairney and Meharg, 1999). Mycorrhizae are integral, functioning parts of plant roots and the fungi involved provide a direct link between soil and roots, and can therefore be of great importance in the availability and toxicity of heavy metals to plants (Leyval et al., 1997). Khan et al. (2000) demonstrated the role of mycorrhiza in phytoremediation of heavy-metal contaminated soils and enhanced uptake of minerals resulting in greater plant biomass. Arsenic is listed as a hazardous material and is a suspect carcinogen (Karim, 2000; Mandal and Suzuki, 2002). Plants growing on As

\footnotetext{
* Corresponding author. Tel.: +86 10 62891325; fax: +86 1062891016
}

E-mail address: lixl@cau.edu.cn (X.L. Li). contaminated soils can form mycorrhiza (Gonzalez-Chavez et al., 2002; Meharg and Hartley-Whitaker, 2002; Sharples et al., 2000a,b). Plants colonized by mycorrhizal fungi displayed enhanced resistance to arsenic (Meharg and Hartley-Whitaker, 2002). Mycorrhizal fungi can play an important role in the acquisition of phosphorus by the host plant, and this may represent a problem on arsenatecontaminated substrates where enhanced uptake of phosphate may also lead to enhanced acquisition of arsenate. Thus, the role of mycorrhizal associations should be taken into account when considering the toxicity of As to plants.

The present study investigated the effects of arbuscular mycorrhizal colonization by Glomus mosseae on As uptake and partitioning in tomato plants growing in As contaminated soil. Tomato was selected because it grows rapidly and may therefore have potential for use as a high-yielding non-hyperaccumulator of As for phytoremediation of con- 
taminated soils. It can be readily colonized by arbuscular mycorrhizal fungi and is a convenient species to use in glasshouse experiments.

\section{Materials and methods}

\subsection{Experimental conditions}

The experiment consisted of a randomized block design with two factors, the mycorrhizal treatment (colonization by Glomus mosseae and non-mycorrhizal control) and As contamination of the soil at rates of $0,25,50,75$ and $150 \mathrm{mg} \mathrm{kg}^{-1}$ in the form of $\mathrm{Na}_{3} \mathrm{AsO}_{4} \cdot 12 \mathrm{H}_{2} \mathrm{O}$ ( $\mathrm{Tu}$ and $\mathrm{Ma}, 2002$ ). Thus, there were 10 treatments in triplicate, giving a total of 30 pots.

The low-phosphorus experimental soil was collected from the field experiment station of Shijiazhuang Institute of Agricultural Modernization and had the following properties: $\mathrm{pH} 7.74$ (soil/ water ratio, 1:2.5), organic matter $1.75 \%$, Olsen-P $4.89 \mathrm{mg} \mathrm{kg}^{-1}$, total As $5.24 \mathrm{mg} \mathrm{kg}^{-1}, 0.5 \mathrm{~mol} \mathrm{~L}^{-1} \mathrm{NaHCO}_{3}$-extractable As 0.07 $\mathrm{mg} \mathrm{kg}^{-1}$. The soil was passed through a $2-\mathrm{mm}$ sieve, autoclaved at $120{ }^{\circ} \mathrm{C}$ for $2 \mathrm{~h}$ and then air-dried. All treatments received a soil application of $200 \mathrm{mg} \mathrm{N}\left(\mathrm{NH}_{4} \mathrm{NO}_{3}\right), 30 \mathrm{mg} \mathrm{P}\left(\mathrm{KH}_{2} \mathrm{PO}_{4} \cdot 2 \mathrm{H}_{2} \mathrm{O}\right)$ and $150 \mathrm{mg} \mathrm{K}\left(\mathrm{K}_{2} \mathrm{SO}_{4}\right) \mathrm{kg}^{-1}$ as a basal fertilizer. Each pot received $500 \mathrm{~g}$ fertilized soil and the pots were stored for 3 weeks after amendment with As solution.

Inoculum of Glomus mosseae (Gerdemann and Trappe) BEG167 comprised a sandy soil containing spores of the fungus together with infected maize root fragments after propagation of the fungus on maize plants grown in the sandy soil for 10 weeks. The spore count of the inoculum was 49 spores/g soil as determined by the wet sieving and decanting method of Gerdemann and Nicolson (1963). Inoculum (15 g) was mixed with the soil of each pot for the mycorrhizal treatment, and $15 \mathrm{~g}$ sterilized inoculum plus $15-\mathrm{mL}$ mycorrhizal fungal-free filtrate from the inoculum suspension were added for the non-mycorrhizal treatment to provide a similar microflora except for the mycorrhizal fungus.

Seeds of tomato (Lycopersicon esculentum L.) were surface sterilized in a $10 \%(\mathrm{v} / \mathrm{v})$ solution of hydrogen peroxide for $10 \mathrm{~min}$. They were pre-germinated for 2 days at $28{ }^{\circ} \mathrm{C}$ and then sown in vermiculite. After growth for 35 days, seedlings were selected and transplanted in $800-\mathrm{mL}$ plastic pots with two seedlings per pot.

The experiment was conducted from October 2002 to January 2003 in a glasshouse at $11-22{ }^{\circ} \mathrm{C}$ without supplementary illumination. The soil moisture in the pots was adjusted daily by weight to about $15 \%(\mathrm{w} / \mathrm{w})$ with deionized water.

\subsection{Harvest and analyses}

Shoots and roots were harvested separately after growth for 60 days. Samples were rinsed twice with deionized water. Portions of fresh roots were collected for determination of mycorrhizal colonization. The dry weights of the shoots and the remaining roots were determined after oven drying at $70{ }^{\circ} \mathrm{C}$ for $48 \mathrm{~h}$. Ground subsamples were digested in a microwave accelerated reaction system (CEM Corporation). A subsample of about 200 mg was accurately weighted into a PTFE pressure vessel and 5 $\mathrm{mL}$ of concentrated $\mathrm{HNO}_{3}$ was added. The microwave digestion program was as follows: power $1200 \mathrm{~W}$, temperature $160{ }^{\circ} \mathrm{C}$, pressure $350 \times 10^{5} \mathrm{~Pa}$, and holding time $15 \mathrm{~min}$. After cooling, the sample solution was transferred with deionized water and filtered into a $50-\mathrm{mL}$ plastic bottle. Arsenic was analyzed by atomic fluorescence spectrometry using a Model AF-610A spectrometer (Beijing Rayleigh Analytical Instrument Co., China) and $\mathrm{P}$ was determined by colorimetry using the standard vanadomolybdate method.

After harvest the soil was sieved $(<1 \mathrm{~mm})$ and soil $\mathrm{pH}$ was measured with a potentiometer (Thermo Orion, Model 868) using a 1:2.5 soil/water ratio. Arsenic is chemically similar to $\mathrm{P}$ and has therefore been evaluated using the same chemical extractant (Rodriguez et al., 2003; Gruebel et al., 1988; Johnson and Barnard, 1979). Soil available As was extracted with $0.5 \mathrm{~mol} \mathrm{~L}^{-1}$ $\mathrm{NaHCO}_{3}$ at $\mathrm{pH} 8.5$ and determined by atomic fluorescence spectrometry.

Mycorrhizal colonization was estimated using the root fragment method of Brundrett et al. (1996). Root samples were cut into 1 -cm-long segments, cleared in $10 \%(\mathrm{w} / \mathrm{v}) \mathrm{KOH}$ at $90{ }^{\circ} \mathrm{C}$ for $1 \mathrm{~h}$ in a water bath, acidified in $2 \%(\mathrm{v} / \mathrm{v}) \mathrm{HCl}$ and then stained with Trypan blue at $90{ }^{\circ} \mathrm{C}$ for $15 \mathrm{~min}$. Thirty root segments from each subsample were observed under the microscope for colonization.

Mycorrhizal contribution to total As or $\mathrm{P}$ acquisition of tomato was calculated by subtracting the As or $\mathrm{P}$ uptake of nonmycorrhizal controls from the value of the corresponding mycorrhizal plants (Li et al., 1991a,b).

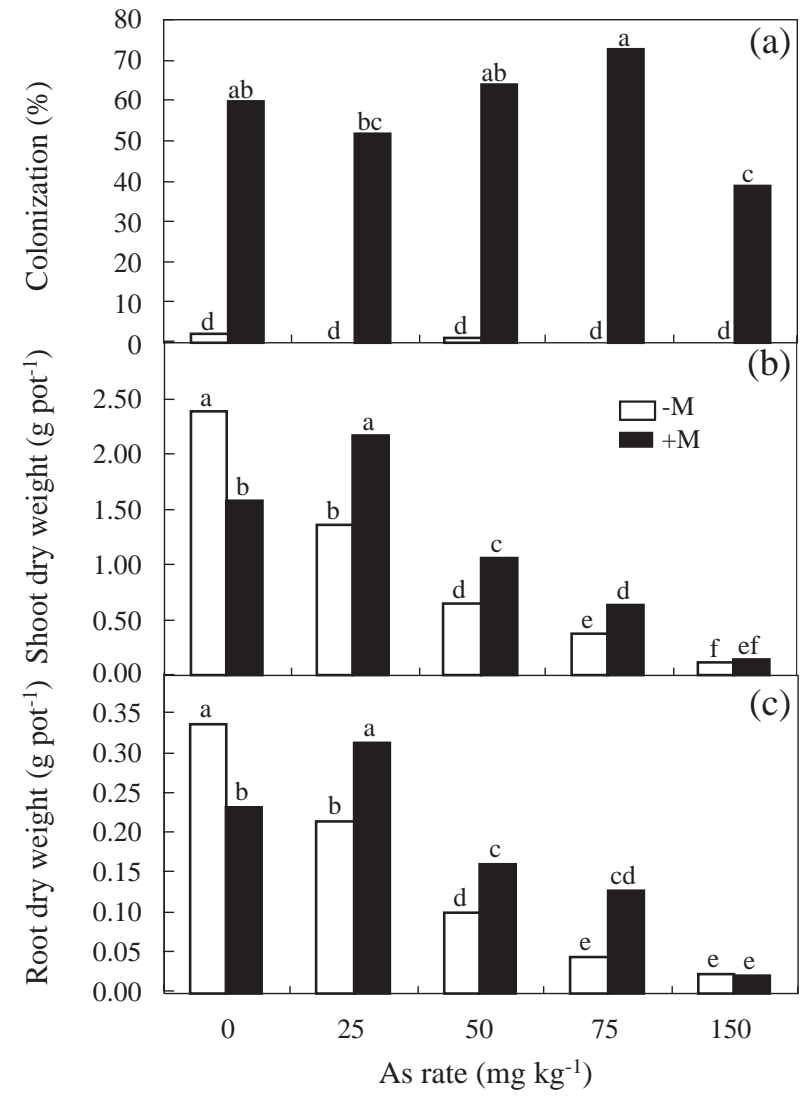

Fig. 1. (a) Mean mycorrhizal colonization, (b) shoot biomass and (c) root biomass of non-mycorrhizal $(-\mathrm{M})$ tomato plants and plants colonized $(+\mathrm{M})$ by Glomus mosseae BEG 167 after 60 days of growth in As contaminated soil. Within each variable, means with the same letter are not significantly different by Duncan's multiple range test at the $5 \%$ level. 


\subsection{Statistical analysis}

Data were tested by two-way analysis of variance with replication with mycorrhizal status and soil As contamination level as the two factors. Mean values were compared using Duncan's multiple range test at the $5 \%$ level.

\section{Results and discussion}

\subsection{Mycorrhizal colonization}

Little root colonization was observed in the uninoculated plants (Fig. 1a). Inoculated plants had over $50 \%$ of the root length colonized with the exception of those in soil with $150 \mathrm{mg} \mathrm{kg}^{-1}$ added As, with a mean of about $40 \%$ of root length colonized (Fig. 1a). Thus G. mosseae BEG 167 produced substantial root colonization at soil As addition levels up to $75 \mathrm{mg} \mathrm{kg}^{-1}$. Increasing As application rate led to higher concentrations of As in the roots (Fig. 2b) and lower yields (Fig. 1b, c). However, mycorrhizal colonization by $G$. mosseae did not appear to be inhibited by As application, with about $70 \%$ of root length colonized even at the As addition level of $75 \mathrm{mg} \mathrm{kg}^{-1}$. The plants had very low yields but still had $39 \%$ of root length colonized in soil to which As was added at the rate of $150 \mathrm{mg} \mathrm{kg}^{-1}$ and soil available As was $55 \mathrm{mg} \mathrm{kg}^{-1}$. Thus, the plants were more sensitive to As than was the AM fungus and the relatively high colonization rates suggest some metal tolerance by the AM fungus. There have been numerous reports of metal tolerant AM fungi in heavy metal polluted soils (Gildon and Tinker, 1983; Hildebrandt et al., 1999; Weissenhorn et al., 1995). High concentrations of heavy metals such as $\mathrm{Cd}$ in soil can inhibit mycorrhizal colonization (Gildon and Tinker, 1983). However, in the present study we did not find any likelihood of As inhibition of mycorrhizal colonization by $G$. mosseae until arsenate was added to the soil at the rate of $75 \mathrm{mg} \mathrm{As}$ $\mathrm{kg}^{-1}$, and the opposite effect occurred at $150 \mathrm{mg} \mathrm{As} \mathrm{kg}^{-1}$. The data indicate that plant tolerance to As contamination may have been enhanced by mycorrhizal colonization. The fungal strain used did not originate from a metal enriched soil, and the question of whether it would function differently on naturally contaminated soils would require further study.

\subsection{Biomass of tomato}

Plant biomass decreased markedly at the elevated As addition levels (Fig. 1b, c). Mycorrhizal colonization increased shoot and root dry weight by more than $30 \%$ at As addition levels of 25,50 and $75 \mathrm{mg} \mathrm{kg}^{-1}$ but decreased biomass of unamended controls and showed no effect at the highest As addition level. Application of lower As rates had little effect on root/shoot ratio (data not shown). Sharples et al. (2001) found similar results with Hymenoscyphus ericae reducing mean yields with increasing $\mathrm{AsO}_{4}^{3-}$ concentration. Negative effects of mycorrhiza on plant yield were observed when no As was applied to the soil. One possible explanation is that relatively large amounts of plant carbohydrates may have been allocated to establishment of the mycorrhizal association and
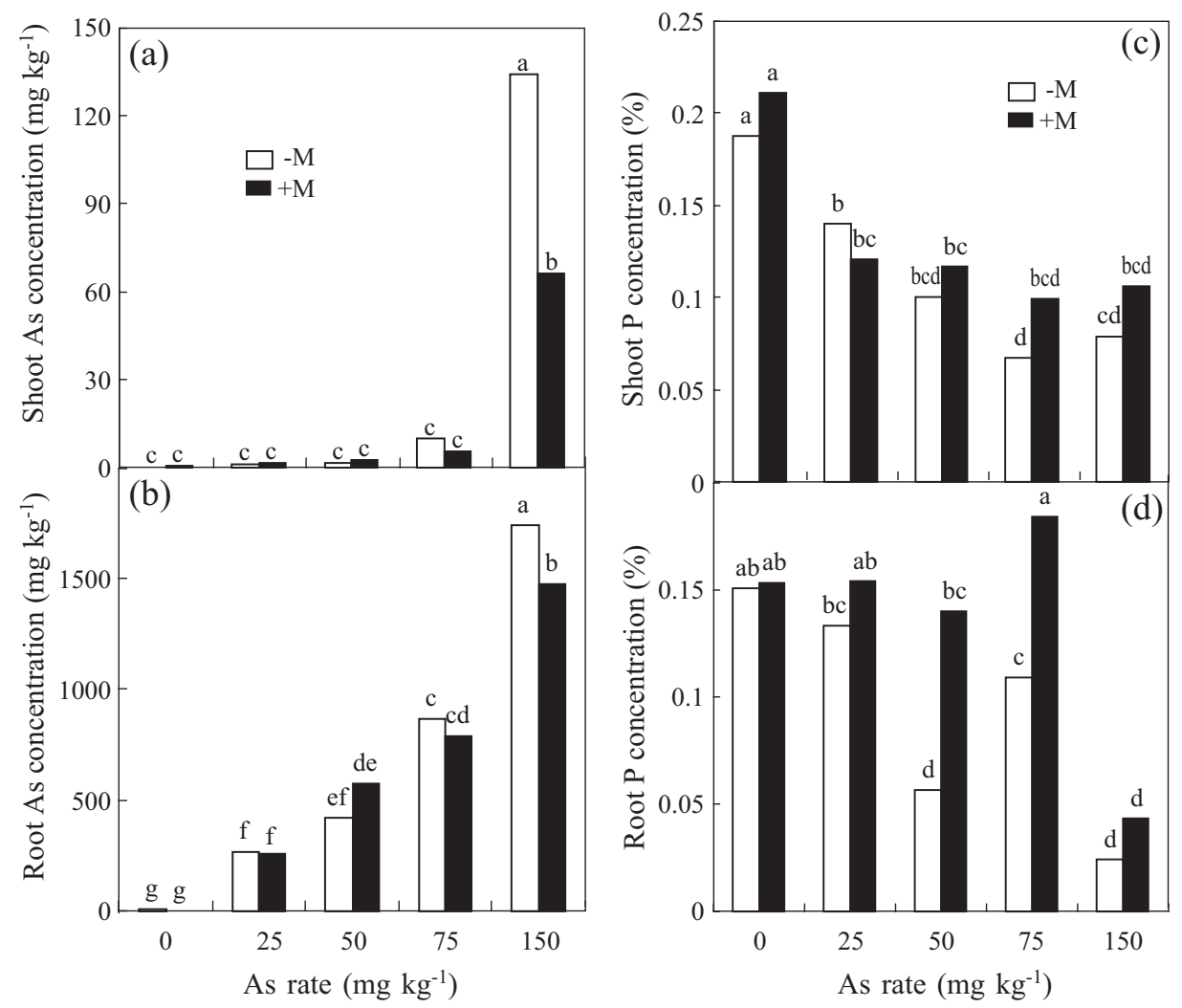

Fig. 2. (a) Mean shoot arsenic and (b) root arsenic concentrations of non-mycorrhizal ( $-\mathrm{M})$ tomato plants and plants colonized (+M) by Glomus mosseae after 60 days of growth in As contaminated soil. (c) Mean shoot phosphorus and (d) root phosphorus concentrations of non-mycorrhizal tomato plants and plants colonized by Glomus mosseae after 60 days of growth in As contaminated soil. 


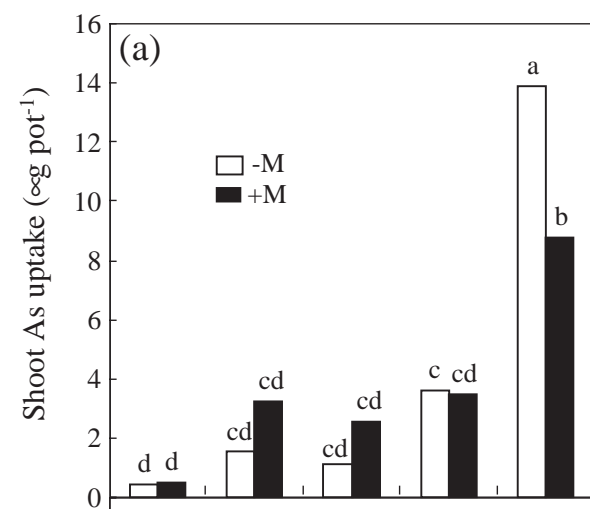

(b)

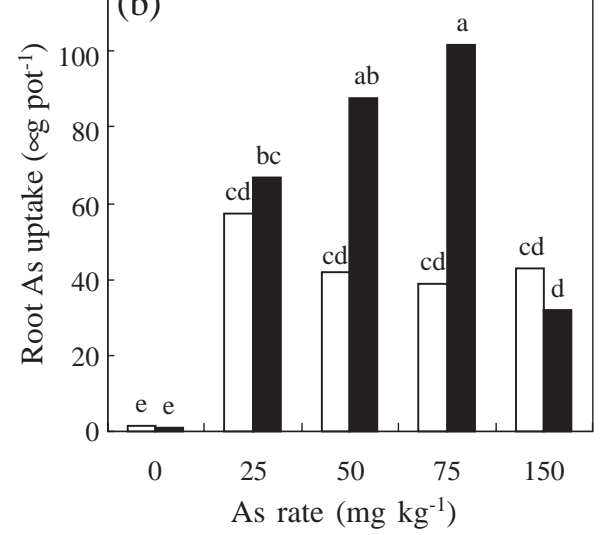

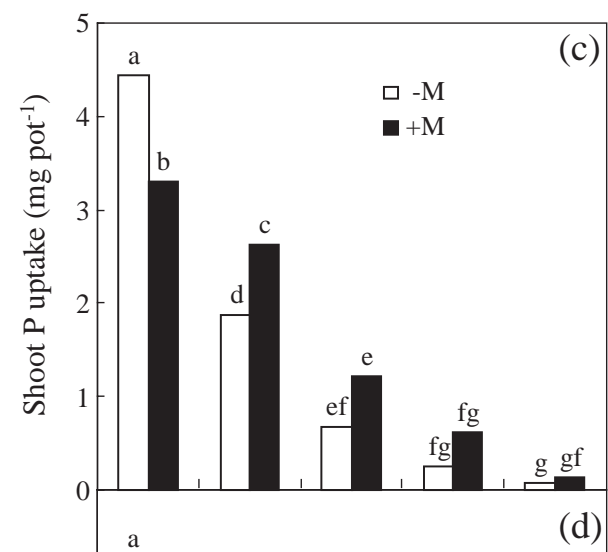

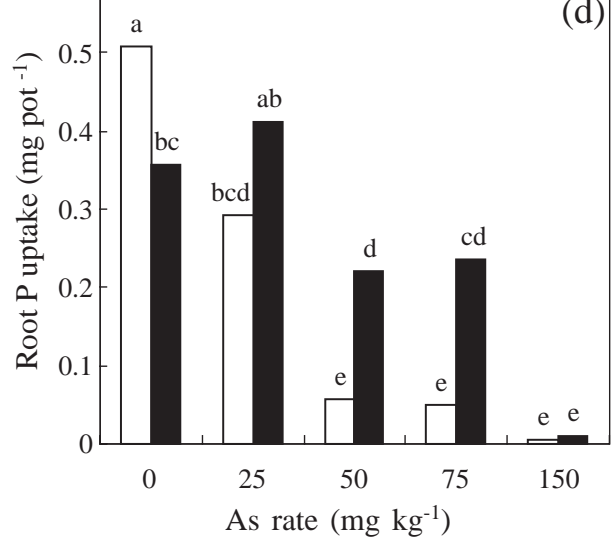

Fig. 3. (a) Mean shoot arsenic and (b) root arsenic uptake of non-mycorrhizal ( $-\mathrm{M})$ tomato plants and plants colonized (+M) by Glomus mosseae after 60 days of growth in As contaminated soil. (c) Mean shoot phosphorus and (d) root phosphorus uptake of non-mycorrhizal tomato plants and plants colonized by Glomus mosseae after 60 days of growth in As contaminated soil.

fungal growth. The most pronounced positive effects of mycorrhiza on plant biomass were observed when As was added to the soil.

\subsection{As and $P$ concentrations in tomato}

Arsenic concentrations were much higher in roots than shoots and increased dramatically in shoots and roots of both non- mycorrhizal and mycorrhizal plants as As addition levels increased (Fig. 2a, b). The maximum concentration of As attained was 1861 $\mathrm{mg} \mathrm{As} \mathrm{kg}^{-1}$ in the roots of one non-mycorrhizal replicate at the highest As addition level. At As addition levels of 0, 25 and $75 \mathrm{mg}$ $\mathrm{kg}^{-1}$, shoot As concentration increased by $23-39 \%$ with mycorrhizal colonization and the opposite trend (45-50\% decrease) occurred at the two highest As application rates. The root concentration was also lower in mycorrhizal plants at the highest (a)

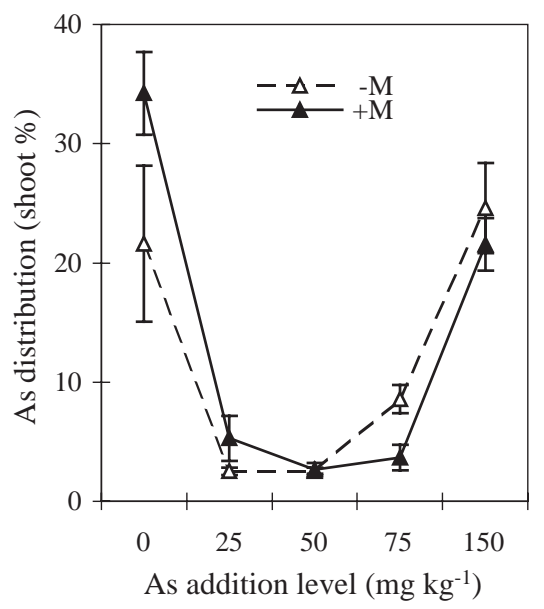

(b)

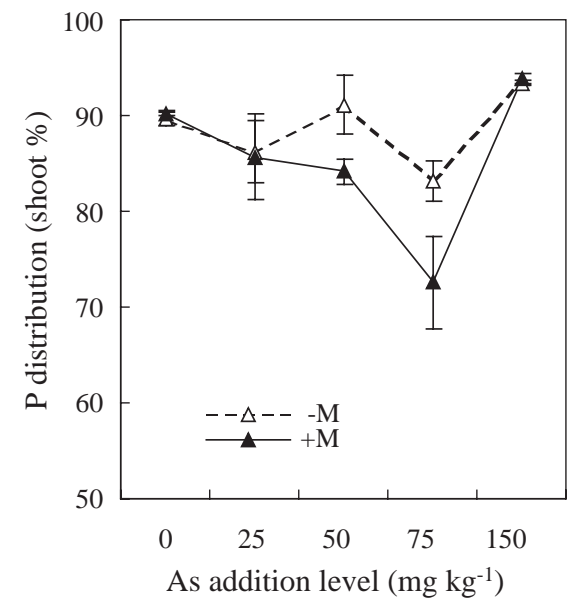

Fig. 4. (a) Arsenic and (b) phosphorus distribution (proportion in the shoots) of mycorrhizal (+M: inoculated with G. mosseae) and non-mycorrhizal (-M) tomato plants at different soil As addition levels. Bars: \pm 1 S.E. 
Table 1

$\mathrm{P}$ uptake/As uptake ratio of non-mycorrhizal tomato plants and plants colonized by Glomus mosseae after 60 days of growth in As contaminated soil

\begin{tabular}{|c|c|c|c|c|c|c|}
\hline \multirow[t]{2}{*}{ P uptake/As uptake } & \multirow[t]{2}{*}{ Mycorrhizal status } & \multicolumn{5}{|c|}{ As rate $\left(\mathrm{mg} \mathrm{kg}^{-1}\right)$} \\
\hline & & 0 & 25 & 50 & 75 & 150 \\
\hline \multirow[t]{2}{*}{ Shoot } & Non-mycorrhizal & $12653 \mathrm{a}$ & $1538 \mathrm{a}$ & $634 \mathrm{a}$ & $79 \mathrm{~b}$ & $6 \mathrm{~b}$ \\
\hline & Mycorrhizal & 7053 a & 864 a & 559 a & $182 \mathrm{a}$ & $17 \mathrm{a}$ \\
\hline \multirow[t]{2}{*}{ Root } & Non-mycorrhizal & $321.1 \mathrm{a}$ & $5.1 \mathrm{a}$ & $1.4 \mathrm{a}$ & $1.4 \mathrm{a}$ & $0.1 \mathrm{~b}$ \\
\hline & Mycorrhizal & $396.0 \mathrm{a}$ & $6.0 \mathrm{a}$ & $2.6 \mathrm{a}$ & $2.4 \mathrm{a}$ & $0.3 \mathrm{a}$ \\
\hline
\end{tabular}

Within non-mycorrhizal and mycorrhizal treatments, means with the same letter are not significantly different by Duncan's multiple range test at the $5 \%$ level.

As application rate. Application of As decreased shoot and root $\mathrm{P}$ concentrations of mycorrhizal and non-mycorrhizal plants (Fig. 2c, d). There were no significant differences between mycorrhizal and non-mycorrhizal plants in shoot $\mathrm{P}$ concentration at any As addition level but root $\mathrm{P}$ concentration was higher with mycorrhizal colonization at As addition levels of 50 and $75 \mathrm{mg} \mathrm{kg}^{-1}$. Enhanced root $\mathrm{P}$ concentrations of mycorrhizal plants indicate that improvement of root $\mathrm{P}$ nutrition may have been a factor conferring enhanced plant growth and tolerance to As in mycorrhizal plants.

Mycorrhizal colonization had no effect on shoot As uptake except at the highest rate of As at which uptake decreased compared with non-mycorrhizal controls (Fig. 3a, b). In contrast, colonization substantially increased root As uptake at As addition levels of 50 and $75 \mathrm{mg} \mathrm{kg}^{-1}$ and had no significant effect on root As uptake at $150 \mathrm{mg} \mathrm{As} \mathrm{kg}^{-1}$. Shoot and root $\mathrm{P}$ uptake by both non-mycorrhizal and mycorrhizal plants decreased dramatically as As addition level increased (Fig. 3c, d). Shoot P uptake was enhanced by mycorrhizal colonization except for the zero-As control in which P uptake was lower in mycorrhizal plants, and root $\mathrm{P}$ uptake showed similar trends. Arsenate can enter plants through their phosphate transporters (Lee, 1982), causing mycorrhizal fungi to enhance both phosphate and arsenate uptake by plants.

Arsenic was distributed mainly in the roots while P occurred mainly in the shoots. Mycorrhizal colonization led to some transfer of As to the shoots at lower soil As levels, with the opposite effect at higher soil As levels (Fig. 4). There was a break point at the added As level of $50 \mathrm{mg} \mathrm{kg}^{-1}$ at which the lowest proportion of As was distributed in the shoots. Some studies have indicated that inoculation of plants with AM fungi restricted the input of arsenic from the soil to the aboveground plant parts (Meharg et al., 1994; Sidibe and Tesarova, 2001). However, under our experimental conditions AM fungal inoculation enhanced shoot As uptake at lower rates of As application to the soil.

Mycorrhizal plants transferred more $\mathrm{P}$ to roots at As addition rates of 50 and $75 \mathrm{mg} \mathrm{kg}^{-1}$ and no difference was found at As rates of 0,25 and $150 \mathrm{mg} \mathrm{kg}^{-1}$. Shoot and root P/As uptake ratios decreased with increasing As application rate (Table 1). Mycorrhizal plants had higher root $\mathrm{P} / \mathrm{As}$ uptake ratios than nonmycorrhizal controls. Shoot P/As uptake ratios of mycorrhizal plants were lower than those of non-mycorrhizal controls at lower soil As levels, with the opposite trend at higher soil As levels. Mycorrhizal colonization greatly increased both total As and total P uptake by plants at As addition levels of 25, 50 and $75 \mathrm{mg} \mathrm{kg}^{-1}$ (Table 2). Table 2 also shows that the mycorrhizal contribution to As and $\mathrm{P}$ uptake in mycorrhizal plants increased following As application except at the highest As application rate. The mycorrhizal contribution to $\mathrm{P}$ uptake was greater than the contribution to As uptake.

Arsenate is thought to be taken up by the phosphate uptake system of the plant (Meharg et al., 1994; Sharples et al., 1999). This indicates that As-P relationships in plants may play a role in the detoxification of environmental arsenate by mutualistic associations such as mycorrhizae (Benson et al., 1981). Under the higher As contamination levels that we studied (75 and $150 \mathrm{mg}$ $\mathrm{kg}^{-1}$ ), mycorrhizal colonization decreased As partitioning to the plant shoots with a consequent decrease in shoot As concentration. There may also have been an indirect detoxification mechanism

Table 2

Mean total As and P uptake of non-mycorrhizal tomato plants and plants colonized by Glomus mosseae after 60 days of growth in As contaminated soil and mycorrhizal (AM) contribution to As and P uptake in mycorrhizal tomato plants

\begin{tabular}{|c|c|c|c|c|c|c|c|}
\hline \multirow[t]{3}{*}{ As rate $\left(\mathrm{mg} \mathrm{kg}^{-1}\right)$} & \multirow[t]{3}{*}{ Mycorrhizal status } & \multicolumn{3}{|l|}{ As uptake } & \multicolumn{3}{|l|}{ P uptake } \\
\hline & & \multirow[t]{2}{*}{ Total $\left(\mu \mathrm{g} \operatorname{pot}^{-1}\right)$} & \multicolumn{2}{|c|}{$\mathrm{AM}_{\text {contribution }}{ }^{\mathrm{a}}$} & \multirow[t]{2}{*}{ Total $\left(\mathrm{mg} \mathrm{pot}^{-1}\right)$} & \multicolumn{2}{|c|}{$\mathrm{AM}$ contribution ${ }^{\mathrm{b}}$} \\
\hline & & & $\left(\mu \mathrm{g} \operatorname{pot}^{-1}\right)$ & $(\%)$ & & $\left(\mathrm{mg} \mathrm{pot}^{-1}\right)$ & $(\%)$ \\
\hline \multirow[t]{2}{*}{0} & Non-mycorrhizal & $2.1 \mathrm{e}^{\mathrm{c}}$ & NA & $\mathrm{NA}^{\mathrm{d}}$ & $4.96 \mathrm{a}$ & NA & NA \\
\hline & Mycorrhizal & $1.4 \mathrm{e}$ & -0.7 & -50.7 & $3.66 \mathrm{~b}$ & -1.3 & -35.5 \\
\hline \multirow[t]{2}{*}{25} & Non-mycorrhizal & $58.6 \mathrm{~cd}$ & NA & NA & $2.17 \mathrm{~d}$ & NA & NA \\
\hline & Mycorrhizal & $70.0 \mathrm{bc}$ & 11.4 & 16.2 & $3.04 \mathrm{c}$ & 0.87 & 28.6 \\
\hline \multirow[t]{2}{*}{50} & Non-mycorrhizal & $43.1 \mathrm{~cd}$ & NA & NA & $0.73 \mathrm{fg}$ & NA & NA \\
\hline & Mycorrhizal & $90.2 \mathrm{ab}$ & 47.1 & 52.2 & $1.43 \mathrm{e}$ & 0.7 & 49.0 \\
\hline \multirow[t]{2}{*}{75} & Non-mycorrhizal & $42.2 \mathrm{~cd}$ & NA & NA & $0.30 \mathrm{gh}$ & NA & NA \\
\hline & Mycorrhizal & $105.0 \mathrm{a}$ & 62.8 & 59.8 & $0.86 \mathrm{f}$ & 0.56 & 65.1 \\
\hline \multirow[t]{2}{*}{150} & Non-mycorrhizal & $56.5 \mathrm{~cd}$ & NA & NA & $0.09 \mathrm{~h}$ & NA & NA \\
\hline & Mycorrhizal & $40.6 \mathrm{~d}$ & -15.9 & -39.0 & $0.15 \mathrm{~h}$ & 0.06 & 40.0 \\
\hline
\end{tabular}

${ }^{\text {a }}$ Calculated by subtracting total As uptake of non-mycorrhizal control plants from total As uptake of mycorrhizal plants at each As application rate.

${ }^{\mathrm{b}}$ Calculated by subtracting total P uptake of non-mycorrhizal control plants from total P uptake of mycorrhizal plants at each As application rate.

${ }^{\mathrm{c}}$ Within each column, means followed by the same letter are not significantly different by Duncan's multiple range test at the $5 \%$ level.

${ }^{\mathrm{d}} \mathrm{NA}$, not applicable for non-mycorrhizal controls. 
(a)

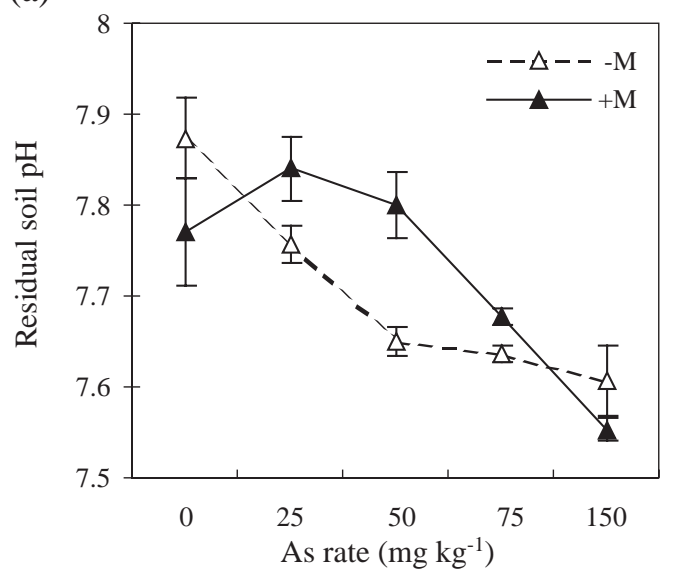

(b)

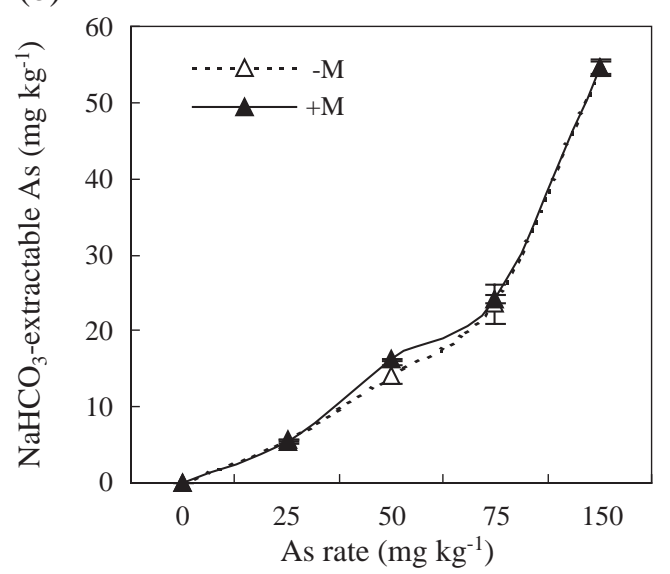

Fig. 5. Residual soil $\mathrm{pH}$ and soil $0.5 \mathrm{~mol} \mathrm{~L}^{-1} \mathrm{NaHCO}_{3}$-extractable As at harvest.

resulting from the 'dilution effect' from enhanced plant $\mathrm{P}$ nutrition and higher yield. Increased root $\mathrm{P}$ concentrations and $\mathrm{P}$ partitioning to roots by mycorrhizal plants may increase competition with As in the roots and restrict As transport to the aerial parts, especially at high As application rates. Several studies have indicated that positive effects of mycorrhiza on host plants under environmental stresses could be directly or indirectly attributed to improved plant $\mathrm{P}$ nutrition, and $\mathrm{P}$ uptake by mycorrhizal plants may have played an role in alleviation of As phytotoxicity. The calculated mycorrhizal contribution to plant total $\mathrm{As}$ and $\mathrm{P}$ acquisition indicates positive effects of mycorrhiza on plant uptake of both As and $\mathrm{P}$ when As was applied to the soil at up to $75 \mathrm{mg} \mathrm{kg}^{-1}$. The highest mycorrhizal contribution to As and $\mathrm{P}$ uptake occurred in the soil amended with $75 \mathrm{mg} \mathrm{As} \mathrm{kg}^{-1}$. Li and Christie (2001) suggested that protective effects of mycorrhiza on host plants were associated with heavy metal immobilization by the mycorrhizal fungi. However, arsenate is an analogue of phosphate (Wauchope, 1975). At the intermediate contamination rates the mycorrhizal fungus may have absorbed As and transported it to the plants, resulting in an increase in As uptake by mycorrhizal plants compared with uninoculated controls. When soils were more heavily contaminated, the effect of mycorrhizal colonization was to reduce plant As concentrations and uptake.

\subsection{Soil $\mathrm{pH}$ and soil available As}

At harvest, the residual soil $\mathrm{pH}$ values of inoculated treatments were higher than those of uninoculated controls at As addition levels of 25, 50 and $75 \mathrm{mg} \mathrm{kg}^{-1}$ (Fig. 5). Residual soil $\mathrm{pH}$ decreased following As application. No differences were observed in $0.5 \mathrm{~mol} \mathrm{~L}^{-1} \mathrm{NaHCO}_{3}$-extractable As between mycorrhizal and uninoculated treatments.

Residual soil $\mathrm{pH}$ values in inoculated treatments were higher than corresponding uninoculated controls at As rates of 25, 50 and $75 \mathrm{mg} \mathrm{kg}{ }^{-1}$ and soil-extractable As concentrations increased slightly. The elevated soil $\mathrm{pH}$ may have increased the mobility and availability of As and thus contributed to the increase in As uptake by the plant roots. However, in bacteria, yeasts and the ericoid mycorrhizal fungus Hymenoscyphus ericae, an enhanced $\mathrm{H}_{3} \mathrm{AsO}_{4}$ efflux system operates as a mechanism for $\mathrm{H}_{2} \mathrm{AsO}_{4}^{-}$ resistance (Doucleff and Terry, 2002; Mukhopadhyay et al., 2000; Mukhopadhyay and Rosen, 2001; Sharples et al., 2000a,b). Thus, elevated $\mathrm{pH}$ in the external medium may have resulted from efflux from mycorrhiza. The slightly higher soil available As concentrations in inoculated treatments compared with uninoculated controls may have been indirect evidence of this.

In conclusion, AM colonization of tomato plants increased plant biomass, As concentration and As uptake at lower levels of soil As contamination, indicating that mycorrhizal plants may be suitable for phytoextraction of As from moderately polluted soil. The AM fungus also appeared to depress shoot As concentrations at higher levels of soil As contamination, and under these conditions may therefore have potential for alleviation of As phytotoxicity in phytostabilization of contaminated sites.

\section{Acknowledgements}

This work was funded by the National Natural Science Foundation of China (Project 30370818), the National High Technology Research and Development Program (863 Program) of the Science Technology Department of the People's Republic of China (Project 2001AA645010-4) and the Royal Society of London (Project 15360).

\section{References}

Benson AA, Cooney RV, Herrera-Lasso LJM. Arsenic metabolism in algae and higher plants. J Plant Nutr 1981;3:285-92.

Brundrett MC, Bougher N, Dell B, Grove T, Malajczuk. Working with mycorrhizas in forestry and agriculture. ACIAR Monogr 1996;32: 373.

Cairney JWG, Meharg AA. Influences of anthropogenic pollution on mycorrhizal fungal communities. Environ Pollut 1999;106:169-82.

Doucleff M, Terry N. Pumping out the arsenic. Nat Biotechnol 2002;20: 1094-5

Gerdemann JW, Nicolson TH. Spores of mycorrhizal Endogone species extracted from soil by wet sieving and decanting. Trans Br Mycol Soc 1963;46:235-44.

Gildon A, Tinker PB. Interactions of vesicular arbuscular mycorrhizal infection and heavy metals in plants: 1 . The effects of heavy metals on the development of vesicular-arbuscular mycorrhizas. New Phytol 1983;95:247-61. 
Gonzalez-Chavez C, Harris PJ, Dodd J, Meharg AA. Arbuscular mycorrhizal fungi confer enhanced arsenate resistance on Holcus lanatus. New Phytol 2002;155:163-71.

Gruebel KA, Davis JA, Leckie JO. The feasibility of using sequential extraction techniques for arsenic and selenium in soils and sediments. Soil Sci Soc Am J 1988;52:390-7.

Hildebrandt U, Kaldorf M, Bothe H. The zinc violet and its colonization by arbuscular mycorrhizal fungi. J Plant Physiol 1999;154:709-17.

Johnson SE, Barnard WM. Comparative effectiveness of fourteen solutions for extracting arsenic from four western New York soils. Soil Sci Soc Am J 1979;43:304-8

Karim MM. Arsenic in groundwater and health problems in Bangladesh. Water Res 2000;34:304-10.

Khan AG, Kuek C, Chaudhry TM, Khoo CS, Hayes WJ. Role of plants, mycorrhizae and phytochelators in heavy metal concentrated land remediation. Chemosphere 2000;41:197-207.

Lee RB. Selectivity and kinetics of ion uptake by barley plants following nutrient deficiency. Ann Bot 1982;50:429-49.

Leyval C, Turnau K, Haselwandter K. Effect of heavy metal pollution on mycorrhizal colonization and function: physiological, ecological and applied aspects. Mycorrhiza 1997;7:139-53.

Li XL, Christie P. Changes in soil solution $\mathrm{Zn}$ and $\mathrm{pH}$ and uptake of $\mathrm{Zn}$ by arbuscular mycorrhizal red clover in Zn-contaminated soil. Chemosphere 2001;42:201-7.

Li XL, George E, Marschner H. Extension of the phosphorus zone in VA-mycorrhizal white clover in a calcareous soil. Plant Soil 1991a; 136:41-8.

Li XL, Marschner H, George E. Acquisition of phosphorus and copper by VA-mycorrhizal hyphae and root to shoot transport in white clover. Plant Soil 1991b;136:49-57.

Mandal BK, Suzuki KT. Arsenic round the world: a review. Talanta 2002;58:201-35.

Meharg AA, Hartley-Whitaker J. Arsenic uptake and metabolism in arsenic resistant and nonresistant plant species. New Phytol 2002;154:29-43.

Meharg AA, Bailey J, Breadmore K, MacNair MR. Biomass allocation, phosphorus nutrition and vesicular-arbuscular mycorrhizal infection in clones of Yorkshire Fog, Holcus lanatus L (Poaceae) that differ in their phosphate uptake kinetics and tolerance to arsenate. Plant Soil 1994; $160: 11-20$

Mukhopadhyay R, Rosen BP. The phosphatase $\mathrm{C}(\mathrm{X})_{5} \mathrm{R}$ motif is required for catalytic activity of the Saccharomyces cerevisiae Acr $2 p$ arsenate reductase. J Biol Chem 2001;276:34738-42.

Mukhopadhyay R, Shi J, Rosen BP. Purification and characterization of Acr2p, the Saccharomyces cerevisiae arsenate reductase. J Biol Chem 2000;275:21149-57.

Rodriguez RR, Basta NT, Casteel SW, Armstrong FP, Ward DC. Chemical extraction methods to assess bioavailable arsenic in soil and solid media. J Environ Qual 2003;32:876-84.

Sharples JM, Meharg AA, Chambers SM, Cairney JWG. Arsenate sensitivity in ericoid and ectomycorrhizal fungi. Environ Toxicol Chem 1999; 18:1848-55.

Sharples JM, Meharg AA, Chambers SM, Cairney JWG. Mechanism of arsenate resistance in the ericoid mycorrhizal fungus Hymenoscyphus ericae. Plant Physiol 2000a;124:1327-34.

Sharples JM, Meharg AA, Chambers SM, Cairney JWG. Evolution symbiotic solution to arsenic contamination. Nature Lond 2000b; 404:951-2.

Sharples JM, Meharg AA, Chambers SM, Cairney JWG. Arsenate resistance in the ericoid mycorrhizal fungus Hymenoscyphus ericae. New Phytol 2001;151:265-70.

Sidibe A, Tesarova M. Effect of inoculation with endomycorrhizal fungi on the growth of selected plants. Acta Univ Agric Silvic Mendel Brun 2001;49:15-20.

Tu C, Ma LQ. Effects of arsenic concentrations and forms on arsenic uptake by the hyperaccumulator ladder brake. J Environ Qual 2002;31:641 - 7 .

Wauchope RD. Fixation of arsenical herbicides, phosphate, and arsenate in soils. J Environ Qual 1975;4:355-8.

Weissenhorn I, Mench M, Leyval C. Bioavailability of heavy metals and arbuscular mycorrhiza in a sewage-sludge-amended sandy soil. Soil Biol Biochem 1995;27:287-96. 